\title{
Less invasive spinal deformity surgery: the impact of the learning curve at tertiary spine care centers
}

\author{
Michael Y. Wang, MD, ${ }^{1}$ Stacie Tran, MPH, ${ }^{2}$ G. Damian Brusko, BS, ${ }^{1}$ Robert Eastlack, MD, ${ }^{3}$ \\ Paul Park, MD, ${ }^{4}$ Pierce D. Nunley, MD, ${ }^{5}$ Adam S. Kanter, MD, ${ }^{6}$ Juan S. Uribe, MD, ${ }^{7}$ Neel Anand, MD, ${ }^{8}$ \\ David O. Okonkwo, MD, PhD, ${ }^{6}$ Khoi D. Than, MD, ${ }^{9}$ Christopher I. Shaffrey, MD, ${ }^{10}$ \\ Virginie Lafage, PhD, ${ }^{11}$ Gregory M. Mundis Jr., MD, ${ }^{12}$ Praveen V. Mummaneni, MD, ${ }^{13}$ and \\ the MIS-ISSG Group
}

'Department of Neurological Surgery, University of Miami Miller School of Medicine, Miami, Florida; ${ }^{2}$ Department of Orthopedic Surgery, San Diego Center for Spinal Disorders, La Jolla, California; ${ }^{2}$ Department of Neurological Surgery, Scripps Clinic Torrey Pines, La Jolla, California; ${ }^{4}$ Department of Neurological Surgery, University of Michigan, Ann Arbor, Michigan; ${ }^{5}$ Department of Orthopedic Surgery, Spine Institute of Louisiana, Shreveport, Louisiana; ${ }^{6}$ Department of Neurological Surgery, University of Pittsburgh Medical Center, Pittsburgh, Pennsylvania; 'Department of Neurosurgery, Barrow Neurological Institute, Phoenix, Arizona; ${ }^{8}$ Department of Orthopedic Surgery, Cedars-Sinai Hospital, Los Angeles, California; ${ }^{9}$ Department of Neurological Surgery, Oregon Health \& Science University, Portland, Oregon; ${ }^{10}$ Department of Neurological Surgery, Duke University, Durham, North Carolina; ${ }^{11}$ Spine Service, Hospital for Special Surgery, New York, New York; ${ }^{12}$ Department of Orthopedic Surgery, Scripps Clinic Torrey Pines, La Jolla, California; and ${ }^{13}$ Department of Neurological Surgery, University of California, San Francisco, California

OBJECTIVE The past decade has seen major advances in techniques for treating more complex spinal disorders using minimally invasive surgery (MIS). While appealing from the standpoint of patient perioperative outcomes, a major impediment to adoption has been the significant learning curve in utilizing MIS techniques.

METHODS Data were retrospectively analyzed from a multicenter series of adult spinal deformity surgeries treated at eight tertiary spine care centers in the period from 2008 to 2015. All patients had undergone a less invasive or hybrid approach for a deformity correction satisfying the following inclusion criteria at baseline: coronal Cobb angle $\geq 20^{\circ}$, sagittal vertical axis $(S V A)>5 \mathrm{~cm}$, or pelvic tilt $>20^{\circ}$. Analyzed data included baseline demographic details, severity of deformity, surgical metrics, clinical outcomes (numeric rating scale [NRS] score and Oswestry Disability Index [ODI]), radiographic outcomes, and complications. A minimum follow-up of 2 years was required for study inclusion.

RESULTS Across the 8-year study period, among 222 patients, there was a trend toward treating increasingly morbid patients, with the mean age increasing from 50.7 to 62.4 years $(p=0.013)$ and the BMI increasing from 25.5 to $31.4 \mathrm{~kg} /$ $\mathrm{m}^{2}(p=0.12)$. There was no statistical difference in the severity of coronal and sagittal deformity treated over the study period. With regard to radiographic changes following surgery, there was an increasing emphasis on sagittal correction and, conversely, less coronal correction. There was no statistically significant difference in clinical outcomes over the 8-year period, and meaningful improvements were seen in all years (ODI range of improvement: 15.0-26.9). Neither were there statistically significant differences in major complications; however, minor complications were seen less often as the surgeons gained experience $(p=0.064)$. Operative time was decreased on average by $47 \%$ over the 8 -year period.

Trends in surgical practice were seen as well. Total fusion construct length was unchanged until the last year when there was a marked decrease in conjunction with a decrease in interbody levels treated $(p=0.004)$ while obtaining a higher degree of sagittal correction, suggesting more selective but powerful interbody reduction methods as reflected by an increase in the lateral and anterior column resection techniques being utilized.

ABBREVIATIONS ACR = anterior column resection; ALIF = anterior lumbar interbody fusion; $A$ SD = adult spinal deformity; LLIF = lateral lumbar interbody fusion; MIS = minimally invasive surgery; MIS-ISSG = MIS section of the International Spine Study Group; NRS = numeric rating scale; ODI = Oswestry Disability Index; PI-LL = pelvic incidence-lumbar lordosis; SVA = sagittal vertical axis.

SUBMITTED May 2, 2019. ACCEPTED June 5, 2019

INCLUDE WHEN CITING Published online August 23, 2019; DOI: 10.3171/2019.6.SPINE19531. 
CONCLUSIONS The use of minimally invasive methods for adult spinal deformity surgery has evolved over the past decade. Experienced surgeons are treating older and more morbid patients with similar outcomes. A reliance on selective, more powerful interbody approaches is increasing as well.

https://thejns.org/doi/abs/10.3171/2019.6.SPINE19531

KEYWORDS minimally invasive; spinal deformity; scoliosis; learning curve; long-term follow-up; surgical technique

$\mathrm{T}$ HE morbidity of adult spinal deformity (ASD) surgery has been well proven through several large multiinstitutional studies. ${ }^{6,9,14}$ Although these operations carry inherent risk, the benefits of such interventions have been shown as well, provided that the tenets of the surgical goals have been met., ${ }^{2,10,11}$ Given these conditions, substantial enthusiasm has been demonstrated for minimally invasive surgery (MIS) options. , $, 7,18,22$ Various technical methods have been developed to achieve these ends, including 1) leveraging alternate access routes, such as with anterior or lateral access surgery; 2) using osteobiologic adjuvants to improve the rates of successful arthrodesis; and 3) using percutaneous fixation methods to obviate the need for extensive muscle dissection.

However, one of the major limitations to the widespread adoption of new techniques has been the issue of training surgeons on proper technique, and there is a substantial learning curve associated with the adoption of newer methods. ${ }^{13}$ Furthermore, when surgical innovation produces new techniques and technologies, the early adopters have limited experience, further complicating matters. ${ }^{1}$

The MIS section of the International Spine Study Group (MIS-ISSG) was formed in 2007 to compile and analyze data from select tertiary spine care centers to evaluate the safety and efficacy of MIS techniques for managing ASD. ${ }^{15,17,20}$ Thus, a review of these centers' experiences as well as their learning curves would serve as an instructive analysis of the history, adoption, and evolution of MIS for ASD in North America.

\section{Methods}

A total of eight tertiary spine care centers with established expertise in ASD MIS were selected to participate in the MIS-ISSG (Fig. 1). All centers obtained local institutional review board approval for participation in this study. Data were collected retrospectively through an annual review process, and data were housed centrally with centralized image processing and analysis. All patients had the following data at baseline (preoperative) and the last follow-up: 36-inch anteroposterior and lateral standing scoliosis radiographs, Oswestry Disability Index (ODI) scores, and separate numeric rating scale (NRS) scores for leg and back pain. The NRS consisted of a 10-point scale. In addition, the database included patient demographics (age, sex, BMI, smoking status, previous spine surgeries, and American Society of Anesthesiologists [ASA] physical status), data for surgical parameters (total operative time, any staging of procedures, total blood loss, surgical methodology, number of levels treated, and routes of approach), and clinical outcomes (length of stay, any blood transfusions, and major or minor complications allocated by subtype).

For inclusion in the database, patients had to be older

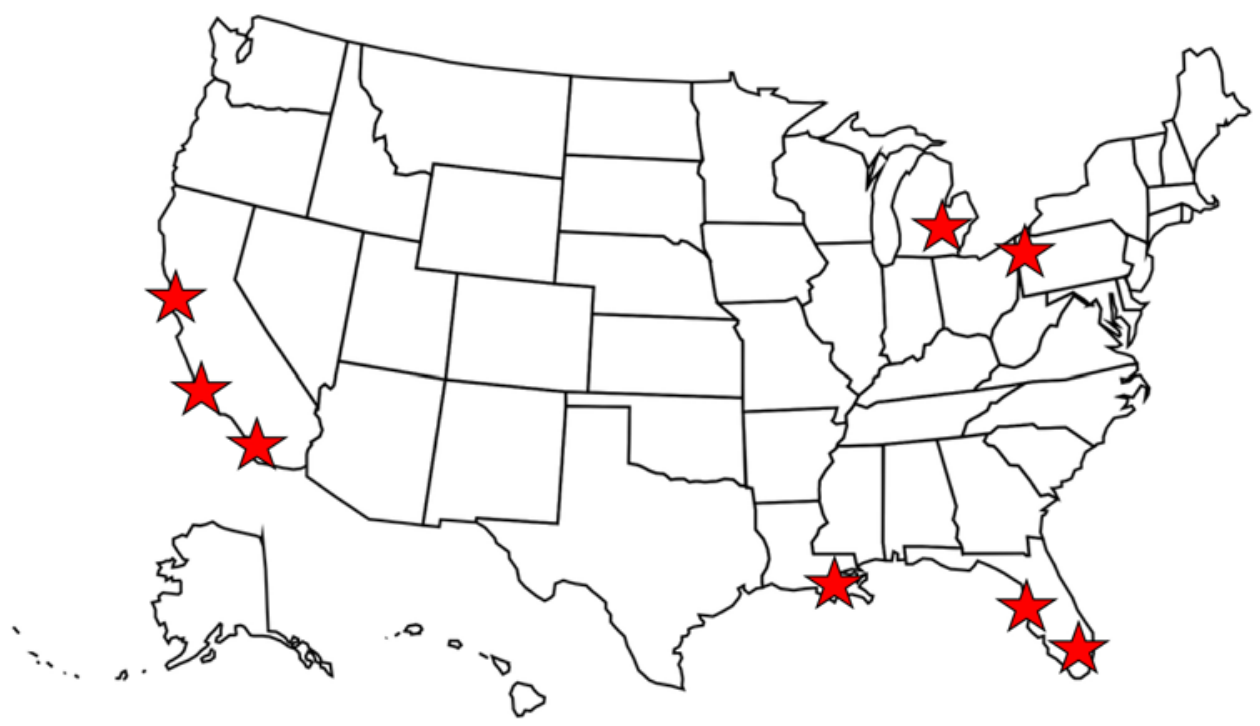

FIG. 1. Enrollment sites for the MIS-ISSG. Map generated with the aid of Pixabay (https://pixabay.com/vectors/usa-map-unitedstates-of-america-35713). Figure is available in color online only. 
TABLE 1. Case enrollment from each spine center by year

\begin{tabular}{lcrrrrrrrr}
\hline & 2008 & 2009 & 2010 & 2011 & 2012 & 2013 & 2014 & 2015 & Total \\
\hline Total & 12 & 26 & 37 & 41 & 35 & 31 & 29 & 11 & 222 \\
\hline Site 1 & 6 & 7 & 7 & 5 & 6 & 0 & 0 & 0 & 31 \\
\hline Site 2 & 1 & 2 & 3 & 1 & 1 & 2 & 3 & 1 & 14 \\
\hline Site 3 & 0 & 3 & 7 & 6 & 4 & 7 & 1 & 1 & 29 \\
\hline Site 4 & 0 & 0 & 1 & 6 & 7 & 7 & 3 & 1 & 25 \\
\hline Site 5 & 0 & 4 & 3 & 5 & 1 & 0 & 0 & 0 & 13 \\
\hline Site 6 & 4 & 5 & 2 & 6 & 3 & 5 & 12 & 1 & 38 \\
\hline Site 7 & 0 & 4 & 13 & 7 & 3 & 3 & 7 & 1 & 38 \\
\hline Site 8 & 1 & 1 & 1 & 5 & 10 & 7 & 3 & 6 & 34 \\
\hline
\end{tabular}

than 18 years of age at the time of surgery. Their standing radiographs had to have a coronal Cobb angle $\geq 20^{\circ}$, pelvic tilt $>20^{\circ}$, or sagittal vertical axis (SVA) $>5 \mathrm{~cm}$. The coronal Cobb angle was determined by measuring the maximal coronal angulation between the two most angulated upper vertebral endplates on 36-inch standing radiographs. Lumbar lordosis was measured between the upper endplates of L1 and S1 in the standing lateral position with 36-inch radiographs. The SVA was measured by dropping a plumb line from the anterior inferior aspect of the C7 vertebra. The minimum distance from this line to the posterior superior endplate of S1 was the SVA measured in centimeters. Data were combined from all centers into an Excel spreadsheet, and data analysis was performed using SPSS software. A minimum of 2 years of clinical and radiographic follow-up was required for inclusion in the study.

\section{Results \\ Patient Series}

Over an 8-year period (2008-2015), eight tertiary spine care centers enrolled 222 patients who underwent less invasive ASD surgery and met the study selection criteria. The distribution of cases is shown in Table 1. A declination in case volume in 2015 occurred with the beginning of enrollment in the prospective component of the MIS-ISSG registry. Over the study period, the average age of surgical patients increased from 50.7 years in 2008 to 62.4 years in 2015 (Table 2). Similarly, more obese patients were treated with time, with the mean BMI increasing from 25.5 to $31.4 \mathrm{~kg} / \mathrm{m}^{2}$. There was no statistical difference in the complexity of the deformity treated (Cobb angle, pelvic incidence-lumbar lordosis [PI-LL] mismatch, or SVA). Two case examples are shown in Figs. 2 and 3.

\section{Surgical Metrics}

No difference was identified in the number of spinal segments reconstructed over the course of the study. However, reductions in operative time were significant, beginning with an average of 525 minutes in 2008 and moving toward a mean of 350 minutes in 2015 . There was no statistical difference in the intraoperative blood loss or acute care length of stay (Table 2).

\section{Clinical and Radiographic Outcomes}

Clinical and radiographic outcomes are shown in Table 3. Overall, improvements were seen in all clinical and radiographic parameters. Meaningful changes were seen in NRS for both leg and back pain in all years. ODI scores improved on average beyond the minimum clinically impor-

TABLE 2. Summary of surgical data

\begin{tabular}{|c|c|c|c|c|c|c|c|c|c|}
\hline Variable & 2008 & 2009 & 2010 & 2011 & 2012 & 2013 & 2014 & 2015 & $p$ Value \\
\hline No. of patients & 12 & 26 & 37 & 41 & 35 & 31 & 29 & 11 & \\
\hline Age (yrs) & 50.67 & 60.81 & 58.99 & 61.77 & 64.26 & 65.74 & 60.07 & 62.36 & 0.013 \\
\hline $\mathrm{BMI}\left(\mathrm{kg} / \mathrm{m}^{2}\right)$ & 25.46 & 25.99 & 27.04 & 27.81 & 28.49 & 27.55 & 28.22 & 31.38 & 0.12 \\
\hline Preop SS $\left(^{\circ}\right)$ & 31.68 & 26.96 & 29.49 & 31.28 & 31.78 & 29.28 & 28.51 & 37.38 & 0.366 \\
\hline Preop PT $\left(^{\circ}\right)$ & 20.42 & 23.13 & 27.58 & 21.81 & 24.03 & 23.30 & 20.19 & 18.88 & 0.144 \\
\hline Preop PI $\left({ }^{\circ}\right)$ & 52.10 & 50.09 & 57.07 & 52.63 & 57.06 & 52.57 & 48.70 & 56.26 & 0.157 \\
\hline Preop PI-LL $\left({ }^{\circ}\right)$ & 9.52 & 15.22 & 20.07 & 15.59 & 14.58 & 20.15 & 9.96 & 10.60 & 0.311 \\
\hline Preop LL $\left({ }^{\circ}\right)$ & 42.58 & 34.87 & 37.00 & 37.91 & 41.60 & 32.42 & 38.74 & 45.66 & 0.355 \\
\hline Preop SVA (cm) & -0.34 & 52.53 & 40.25 & 43.06 & 44.57 & 61.61 & 39.13 & 63.83 & 0.162 \\
\hline Preop max Cobb angle $\left(^{\circ}\right)$ & 39.45 & 41.66 & 34.13 & 34.05 & 32.31 & 27.41 & 28.06 & 31.19 & 0.092 \\
\hline Preop NRS back pain score & 6.75 & 5.96 & 6.97 & 6.80 & 6.97 & 7.10 & 7.14 & 7.88 & 0.329 \\
\hline Preop NRS leg pain score & 5.17 & 5.89 & 5.29 & 6.00 & 5.85 & 5.33 & 5.82 & 6.93 & 0.777 \\
\hline $\mathrm{EBL}(\mathrm{ml})$ & 1254.17 & 983.27 & 1153.92 & 713.78 & 809.41 & 878.87 & 673.62 & 423.64 & 0.381 \\
\hline OR time (mins) & 525.42 & 546.77 & 577.42 & 447.20 & 541.82 & 490.81 & 401.48 & 350.18 & 0.015 \\
\hline LOS (days) & 9.92 & 7.77 & 8.03 & 7.17 & 7.34 & 7.97 & 6.76 & 7.64 & 0.610 \\
\hline Total no. of levels & 7.00 & 6.46 & 6.11 & 5.76 & 6.00 & 6.19 & 6.00 & 3.73 & 0.673 \\
\hline
\end{tabular}

$\mathrm{EBL}=$ estimated blood loss; $\mathrm{LL}=$ lumbar lordosis; $\mathrm{LOS}=$ length of stay; $\mathrm{OR}=$ operating room; $\mathrm{PI}=$ pelvic incidence; $\mathrm{PT}=$ pelvic tilt; $\mathrm{SS}=$ sacral 


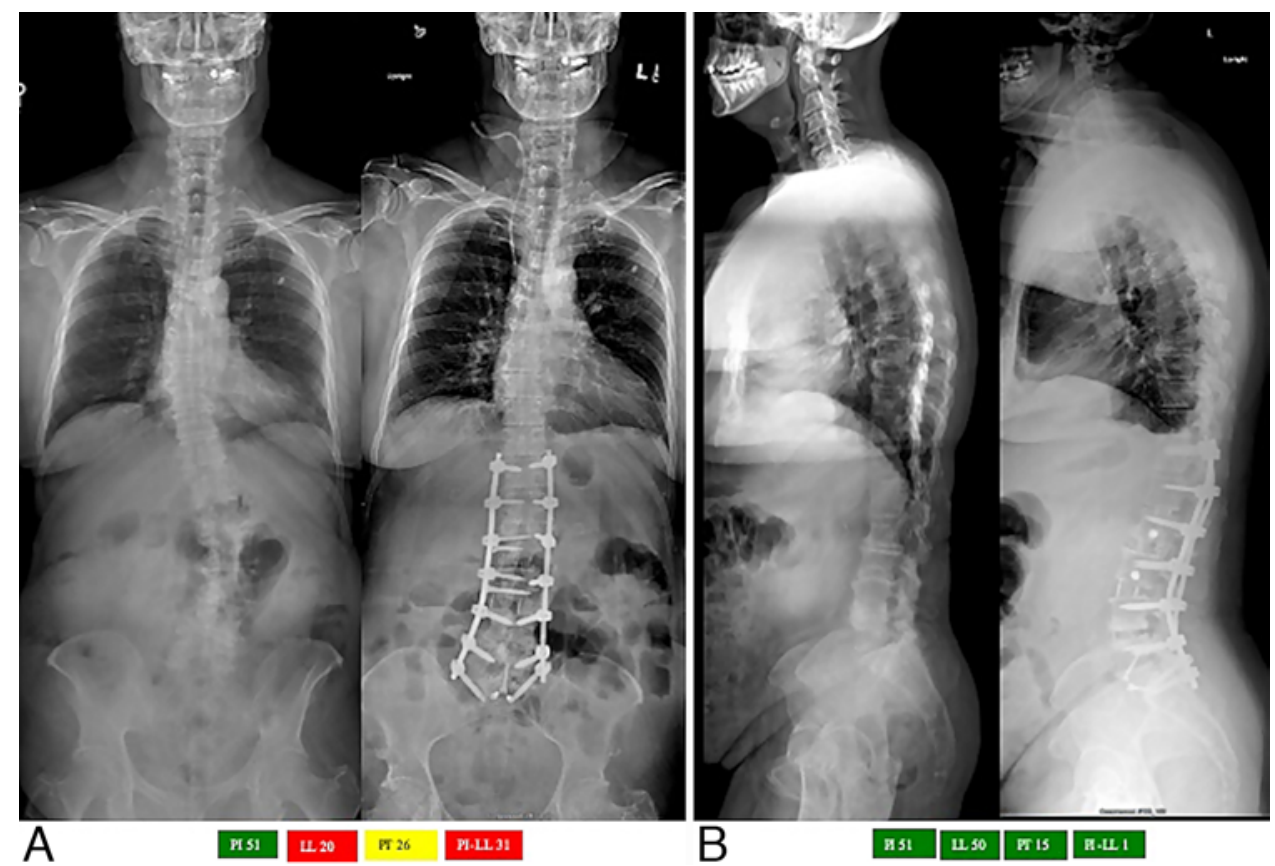

FIG. 2. Surgical case example of early experiences using longer constructs for ASD MIS. Preoperative (left) and postoperative (right) 36-inch anteroposterior (A) and lateral (B) standing scoliosis radiographs illustrate multilevel placement of interbody cages via an LLIF approach to achieve adequate lordosis. Preoperative and postoperative spinopelvic parameters are provided beneath the radiographs. Figure is available in color online only.

tant difference at all years, and no trend was seen for improvements in ODI scores as surgeons gained experience.

Radiographic improvements were seen in the coronal Cobb angle with a slight trend toward lower improvement rates later in the series. However, a decrease in the degree of scoliosis at baseline was also seen over time. Improvements in lordosis as well as the PI-LL mismatch were also seen at all years, with no trends identified (Table 3).
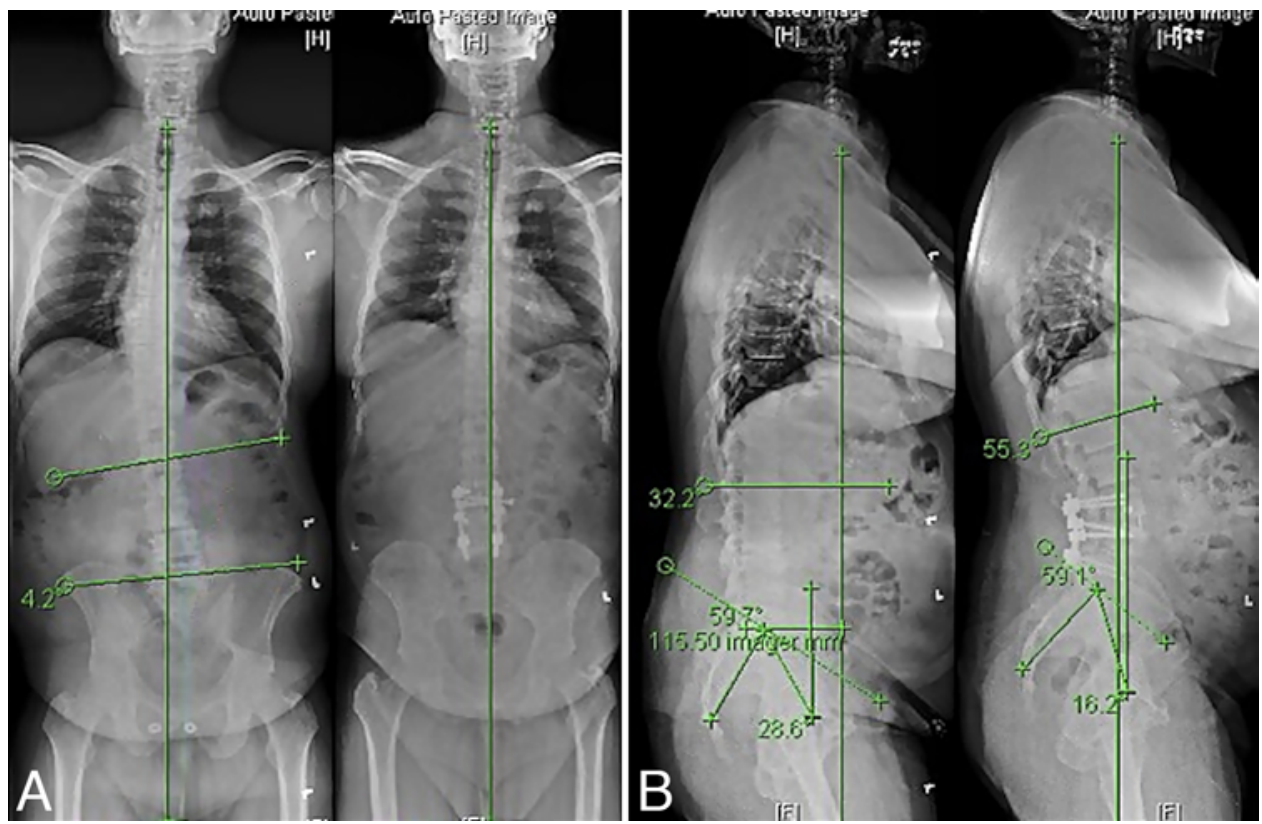

FIG. 3. Surgical case example of later experiences using shorter constructs but more powerful methods for ASD MIS. Preoperative (left) and postoperative (right) 36-inch anteroposterior (A) and lateral (B) standing scoliosis radiographs illustrate the use of fewer interbody cages and combined ALIF and ACR approaches to achieve adequate lordosis. Spinopelvic parameters are provided. Figure is available in color online only. 
TABLE 3. Clinical and radiographic outcomes by year

\begin{tabular}{|c|c|c|c|c|c|c|c|c|c|}
\hline Variable & 2008 & 2009 & 2010 & 2011 & 2012 & 2013 & 2014 & 2015 & $p$ Value \\
\hline No. of patients & 12 & 26 & 37 & 41 & 35 & 31 & 29 & 11 & \\
\hline$\Delta S S\left({ }^{\circ}\right)$ & -5.53 & -0.31 & 0.99 & 0.59 & 0.82 & 3.50 & -3.55 & -0.29 & 0.043 \\
\hline$\Delta \mathrm{PT}\left({ }^{\circ}\right)$ & 5.63 & 0.54 & -1.15 & -0.28 & -0.09 & -1.79 & 3.59 & 1.50 & 0.1 \\
\hline$\Delta \mathrm{PI}\left({ }^{\circ}\right)$ & 0.09 & 0.23 & -0.16 & 0.39 & 0.27 & 1.72 & 0.04 & 1.21 & 0.599 \\
\hline$\Delta \mathrm{PI}-\mathrm{LL}\left({ }^{\circ}\right)$ & 4.85 & -6.54 & -6.29 & -4.80 & -4.64 & -8.51 & -0.35 & -9.09 & 0.384 \\
\hline$\Delta \mathrm{LL}\left({ }^{\circ}\right)$ & -4.75 & 6.76 & 6.12 & 4.97 & 4.71 & 10.22 & 0.38 & 10.30 & 0.264 \\
\hline$\Delta S V A(\mathrm{~cm})$ & 25.41 & -18.16 & 6.28 & 0.20 & 0.94 & -8.31 & 4.62 & -35.22 & 0.415 \\
\hline$\Delta \operatorname{Max}$ Cobb angle $\left(^{\circ}\right)$ & -18.03 & -21.57 & -18.63 & -13.05 & -16.43 & -16.41 & -9.20 & -4.85 & 0.099 \\
\hline$\Delta N R S$ back pain & -0.25 & -3.22 & -4.01 & -2.90 & -3.54 & -3.13 & -2.75 & -3.79 & 0.274 \\
\hline$\Delta$ NRS leg pain & -3.45 & -4.14 & -2.64 & -3.22 & -3.43 & -2.82 & -3.38 & -3.92 & 0.898 \\
\hline$\Delta \mathrm{ODI}$ & -26.90 & -25.34 & -16.79 & -15.00 & -18.33 & -18.04 & -20.85 & -21.82 & 0.461 \\
\hline
\end{tabular}

Boldface type indicates statistical significance.

\section{Complications}

A breakdown of surgical and postoperative complications is shown in Table 4. Overall, complications were common and similar to those in other retrospective series in the medical literature. In general, complication rates were not statistically different between years. However, there was a trend toward a reduction in minor complications $(p=0.064)$ over the course of the study.

\section{Trends in Technical Practice Over 8 Years}

Over the 8-year period, changes in surgical practice were identified (Table 5). Except for the last year, the number of levels for a construct or interbody fusion levels did not differ. In 2015 the number of levels treated decreased from approximately 6 or more levels to 3.73 , and interbody levels decreased from approximately 3 or more to 1.91 ; this included a decrease in lateral lumbar interbody fusion (LLIF) levels treated per patient.

Notably, there were, on average, greater changes in the PI-LL mismatch and SVA despite the decreased number of levels treated. This finding is best explained by surgeons' greater selectivity in choosing interbody levels and achievement of greater correction per interbody level. The increase in anterior column resection (ACR) from $0 \%$ to $36.4 \%$ of cases likely accounts for this finding. In contrast to the sagittal correction, less coronal correction was noted on average in 2015 , which is likely attributable to the decreased number of levels treated. There was also an increase in the use of anterior lumbar interbody fusion (ALIF) for sagittal correction.

When exploring the broad categories of ASD MIS initially used by the MIS-ISSG, $, 16,20$ we saw certain trends. In summary, the groups included 1) circumferential MIS (cMIS), which includes ALIF and/or LLIF with percutaneous screws; 2) percutaneous MIS (pMIS), TLIF with percutaneous screws or percutaneous screws only with no interbody fusion; 3) stand alone, LLIF only; and 4) hybrid (HYB), any interbodies with open posterior surgery. While none of the trends was statistically significant, the use of both stand-alone and HYB surgery decreased over the years (Table 5).

TABLE 4. Surgical and postoperative complications by year

\begin{tabular}{lrrrrrrrrr}
\hline \multicolumn{1}{c}{ Variable } & 2008 & 2009 & 2010 & 2011 & 2012 & 2013 & 2014 & 2015 & $p$ Value \\
\hline No. of patients & \multicolumn{1}{c}{12} & \multicolumn{1}{c}{26} & \multicolumn{1}{c}{37} & \multicolumn{1}{c}{41} & \multicolumn{1}{c}{35} & 31 & \multicolumn{1}{c}{29} & 11 \\
\hline Complications & $33.3 \%$ & $42.3 \%$ & $59.5 \%$ & $43.9 \%$ & $42.9 \%$ & $58.1 \%$ & $48.3 \%$ & $18.2 \%$ & 0.249 \\
\hline Reoperations & $25.0 \%$ & $26.9 \%$ & $40.5 \%$ & $22.0 \%$ & $25.7 \%$ & $16.1 \%$ & $20.7 \%$ & $0.0 \%$ & 0.166 \\
\hline Major & $25.0 \%$ & $26.9 \%$ & $35.1 \%$ & $24.4 \%$ & $25.7 \%$ & $32.3 \%$ & $10.3 \%$ & $9.1 \%$ & 0.358 \\
\hline Minor & $16.7 \%$ & $38.5 \%$ & $51.4 \%$ & $34.1 \%$ & $34.3 \%$ & $54.8 \%$ & $44.8 \%$ & $9.1 \%$ & 0.064 \\
\hline Infection & $0.0 \%$ & $7.7 \%$ & $13.5 \%$ & $2.4 \%$ & $8.6 \%$ & $9.7 \%$ & $0.0 \%$ & $9.1 \%$ & 0.369 \\
\hline Implant & $8.3 \%$ & $3.8 \%$ & $18.9 \%$ & $17.1 \%$ & $8.6 \%$ & $16.1 \%$ & $20.7 \%$ & $0.0 \%$ & 0.366 \\
\hline Radiographic & $25.0 \%$ & $23.1 \%$ & $24.3 \%$ & $14.6 \%$ & $22.9 \%$ & $29.0 \%$ & $24.1 \%$ & $0.0 \%$ & 0.583 \\
\hline Surgical site & $16.7 \%$ & $3.8 \%$ & $8.1 \%$ & $0.0 \%$ & $2.9 \%$ & $0.0 \%$ & $0.0 \%$ & $0.0 \%$ & 0.366 \\
\hline Neurological & $0.0 \%$ & $15.4 \%$ & $18.9 \%$ & $22.0 \%$ & $11.4 \%$ & $19.4 \%$ & $13.8 \%$ & $0.0 \%$ & 0.453 \\
\hline Cardiovascular & $0.0 \%$ & $7.7 \%$ & $16.2 \%$ & $4.9 \%$ & $5.7 \%$ & $6.5 \%$ & $3.4 \%$ & $9.1 \%$ & 0.474 \\
\hline Gastroenterological & $0.0 \%$ & $3.8 \%$ & $2.7 \%$ & $0.0 \%$ & $5.7 \%$ & $3.2 \%$ & $0.0 \%$ & $0.0 \%$ & 0.719 \\
\hline Operative & $0.0 \%$ & $7.7 \%$ & $10.8 \%$ & $0.0 \%$ & $2.9 \%$ & $9.7 \%$ & $0.0 \%$ & $0.0 \%$ & 0.158 \\
\hline
\end{tabular}


TABLE 5. Surgical and technical trends in practice over 8 years

\begin{tabular}{|c|c|c|c|c|c|c|c|c|c|}
\hline Variable & 2008 & 2009 & 2010 & 2011 & 2012 & 2013 & 2014 & 2015 & $p$ Value \\
\hline \multicolumn{10}{|l|}{ Surgical trends } \\
\hline Total no. of levels & 7.00 & 6.46 & 6.11 & 5.76 & 6.00 & 6.19 & 6.00 & 3.73 & 0.673 \\
\hline No. of IBF levels & 3.42 & 3.92 & 3.05 & 2.85 & 3.47 & 3.39 & 2.83 & 1.91 & 0.004 \\
\hline No. of pst levels & 6.92 & 5.77 & 5.62 & 5.15 & 5.60 & 6.13 & 5.93 & 3.18 & 0.557 \\
\hline ALIF ( $\%$ cases) & 0.0 & 7.7 & 10.8 & 17.1 & 20.0 & 25.8 & 13.8 & 36.4 & 0.167 \\
\hline No. of ALIF levels/patient & 0.00 & 0.19 & 0.19 & 0.24 & 0.31 & 0.58 & 0.28 & 0.64 & 0.173 \\
\hline LLIF (\% cases) & 91.7 & 84.6 & 70.3 & 63.4 & 74.3 & 77.4 & 72.4 & 45.5 & 0.168 \\
\hline No. of LLIF levels/patient & 3.00 & 3.12 & 2.32 & 2.00 & 2.37 & 2.32 & 2.00 & 1.09 & 0.029 \\
\hline TLIF ( $\%$ cases) & 8.30 & 30.8 & 32.4 & 34.1 & 37.1 & 41.9 & 37.9 & 18.2 & 0.522 \\
\hline No. of TLIF levels/patient & 0.08 & 0.54 & 0.51 & 0.61 & 0.49 & 0.52 & 0.55 & 0.18 & 0.695 \\
\hline ACR ( $\%$ cases) & 0.0 & 0.0 & 0.0 & 19.5 & 28.6 & 19.4 & 10.3 & 36.4 & 0.001 \\
\hline $3 \mathrm{CO}(\%$ cases $)$ & 0.0 & 11.5 & 27.0 & 7.3 & 2.9 & 3.2 & 0.0 & 9.1 & 0.002 \\
\hline SPO ( $\%$ cases $)$ & 41.7 & 38.5 & 43.2 & 34.1 & 17.1 & 25.8 & 27.6 & 0.0 & 0.212 \\
\hline VCR ( $\%$ cases) & 0.0 & 0.0 & 0.0 & 0.0 & 0.0 & 3.2 & 0.0 & 0.0 & 0.518 \\
\hline \multicolumn{10}{|l|}{ Technical trends } \\
\hline No. of patients & 12 & 26 & 37 & 41 & 35 & 31 & 29 & 11 & \\
\hline Approach (\% cases) & & & & & & & & & 0.372 \\
\hline cMIS & 50.0 & 61.5 & 35.1 & 46.3 & 54.3 & 54.8 & 44.8 & 54.5 & \\
\hline HYB & 50.0 & 30.8 & 51.4 & 39.0 & 37.1 & 35.5 & 41.4 & 27.3 & \\
\hline pMIS & 0.0 & 0.0 & 5.4 & 2.4 & 5.7 & 6.5 & 13.8 & 18.2 & \\
\hline Stand alone & 0.0 & 7.7 & 8.1 & 12.2 & 2.9 & 3.2 & 0.0 & 0.0 & \\
\hline
\end{tabular}

$3 \mathrm{CO}=3$-column osteotomy; $\mathrm{CMIS}=$ circumferential MIS; $\mathrm{HYB}=$ hybrid; IBF = interbody fusion; $\mathrm{pMIS}$ = percutaneous MIS; pst = posterior; SPO $=$ Smith-Petersen osteotomy; TLIF = transforaminal lumbar interbody fusion; $\mathrm{VCR}=$ vertebral column resection.

Boldface type indicates statistical significance.

\section{Discussion}

The pace of change in surgical strategy and technique has been rapid for spinal surgeons. Only 2 decades ago, we saw the advent of the simplest minimally invasive spinal fusion procedures, and now it is not uncommon for complex fusions to be performed for spinal deformities. To date, however, most of the literature has served as a validation or assessment of one particular approach or technique. One value of a multiinstitutional cohort is the ability to examine practices over a wide swath of providers. To this end, the MIS-ISSG has been exploring the practice patterns at tertiary spine care centers for the past decade. We believe that this study represents real-world practices when surgeons attempt to address ASD through a less invasive approach.

\section{Effects of Surgical Experience}

At its inception, the MIS-ISSG was formed from a core group of practitioners already committed to the concept of less invasive deformity treatment. Nonetheless, our data demonstrate that even at these specialty centers, there was ample opportunity for improvement. As surgical experience was accrued, the speed of surgery was increased, as indicated by the reduction in operative time between the first and last year. Although the decreased number of levels treated likely contributed to the rather dramatic decrease in OR time to a mean of 350.2 minutes in 2015, in prior years there was a decrease to under 500 minutes even while surgical construct length was relatively unchanged at an average of almost 6 segmental levels.

This trend occurred concomitantly with a shifting of the treated population to more elderly and obese patients. In fact, this reflects the general trend seen in minimally invasive spinal surgery for degenerative pathologies. ${ }^{12,21}$ While it is clear that more powerful reduction methods are likely possible with open surgery versus MIS, one of MIS's unique advantages is the opportunity to treat patients who are more frail and thus less likely to be candidates for traditional open operations. With the changes seen in North American demographics, MIS options for deformity may be needed in an ever-aging and debilitated ASD population. ${ }^{8,9}$ This may also account for the relative stability in operative blood loss and hospital length of stay. We suspect the reduction in complications has been the result of three major factors. The first has been the reduction in surgical time and construct length, the second has likely been the accrual of surgical experience, and the third has been an improvement in patient selection.

\section{Trends in Surgical Decision-Making}

Over the time course of this study, we also saw significant changes in surgical practices. The history of modern minimally invasive spinal fusion parallels that of the evolution of interbody fusion. In the early years of this 
study, there was a heavy reliance on the use of multiple lateral interbody fusion cages to gain correction as well as achieve successful arthrodesis. Toward the end of the study, we saw a reduction in the number of interbody levels instrumented with an overall increase in sagittal correction. However, there was a decrease in coronal correction, which is not surprising given the decreased number of levels treated. This is likely the result of a number of associated factors, including 1) an increased confidence in the ability to achieve successful arthrodesis without a wide posterolateral exposure, 2) more selective identification of key spinal segments that could benefit from interbody distraction and cage placement, 3) a trend toward more ALIF surgery with its ability to gain harmonious lordosis restoration, 4) the development of ACR lateral surgery, and 5) a likely de-emphasis on treating the coronal curve so long as coronal balance is maintained or restored.

These trends are notable in that they represent a maturation in the field of ASD MIS. The advent of commercially available hyperlordotic ALIF and ACR cages has led to a trend away from three-column osteotomy surgery as well as the need for segmental correction over numerous spinal levels. Some of these changes in practice have been incorporated into a new algorithm for surgical decision-making, as described in a previous publication by our group. ${ }^{3}$

Whether these trends will continue has yet to be ascertained. It should be noted that even within these eight centers, there was a high degree of heterogeneity with regard to the techniques employed. Some centers have shown that with strict staged protocols, ALIF at L5-S1 and appropriate placement of interbody cages anteriorly can be used, and they have not utilized lateral ACR techniques to obtain optimal spinal balance. ${ }^{1}$ Others have favored less invasive posterior osteotomy techniques. ${ }^{19}$

\section{Future Directions}

While we have seen significant changes in practice patterns at our institutions over the study period, we recognize that additional changes and improvements will be coming and are indeed necessary. Major technological improvements in enhancing fusion and bony fixation and in preventing adjacent level disease are, of course, needed, but it will be difficult to predict what new developments will prove effective in the realm of MIS.

Nonetheless, there are several areas that could be expanded upon in the near future. One such area is the ability of surgeons to treat patients who have preexisting spinal implants. Current implant extraction methods typically require some form of open surgery, limiting the application of minimally invasive approaches. In the future, methods for the removal of titanium implants without a large exposure, fixation around existing pedicle screw-rod constructs, or attachment/incorporation onto existing structures could all allow for a minimally invasive approach in revision cases.

Another area in which ASD MIS suffers as compared with open surgery is in the use of posterior column or Ponte osteotomies. A growing contingent of deformity experts has been advocating for these less disruptive means of mobilizing a stiff spine, as this approach reduces the high morbidity that is concomitant with anterior column osteot- omies. The need for exposure of the facets and lamina bilaterally and at multiple spinal levels has limited the application of these techniques in MIS for ASD. However, the advent of bone-cutting wires and harmonic technologies has begun to provide an opportunity for the development of a method for minimally invasive posterior osteotomies.

Finally, there has been a limitation in applying corrective mechanical forces with MIS. While some methods do exist, they are largely restricted to mechanical actuators incorporated on the rods and screw heads themselves. In traditional open deformity surgery, one has the ability to apply compression/distraction, in situ rod bending, and translational forces, all powerful corrective adjuncts. Advances in spinal instrumentation are likely to provide opportunities for applying these same techniques in MIS.

\section{Study Limitations}

As with all retrospective studies, this report has significant limitations. Nonetheless, data collection occurred on an annual basis, and the data likely reflect true physician practices and outcomes at these eight centers. Other inherent limitations relate to sample size and lack of statistical power to validate some of the trends seen in this series.

Another drawback of this study was its limitation to eight selective centers. Thus, it is unclear if this report represents practice patterns across North America. Unfortunately, larger data sets lack granular data elements and would be unlikely to detect some of the findings seen in this multicenter study.

\section{Conclusions}

This study represents one of the first publications examining the learning curve in complex spinal MIS. Our findings suggest that opportunities for improvement exist at highly specialized referral centers and that the field of ASD MIS has been evolving substantially.

\section{References}

1. Anand N, Cohen JE, Cohen RB, Khandehroo B, Kahwaty S, Baron E: Comparison of a newer versus older protocol for circumferential minimally invasive surgical (CMIS) correction of adult spinal deformity (ASD)-evolution over a 10-year experience. Spine Deform 5:213-223, 2017

2. Choi SH, Son SM, Goh TS, Park W, Lee JS: Outcomes of operative and nonoperative treatment in patients with adult spinal deformity with a minimum 2-year follow-up: a metaanalysis. World Neurosurg 120:e870-e876, 2018

3. Choy W, Miller CA, Chan AK, Fu KM, Park P, Mummaneni PV: Evolution of the minimally invasive spinal deformity surgery algorithm: an evidence-based approach to surgical strategies for deformity correction. Neurosurg Clin N Am 29:399-406, 2018

4. Haque RM, Mundis GM Jr, Ahmed Y, El Ahmadieh TY, Wang MY, Mummaneni PV, et al: Comparison of radiographic results after minimally invasive, hybrid, and open surgery for adult spinal deformity: a multicenter study of 184 patients. Neurosurg Focus 36(5):E13, 2014

5. Kanter AS, Tempel ZJ, Ozpinar A, Okonkwo DO: A review of minimally invasive procedures for the treatment of adult spinal deformity. Spine (Phila Pa 1976) 41 (Suppl 8):S59S65, 2016

6. Lenke LG, Fehlings MG, Shaffrey CI, Cheung KM, Carreon 
L, Dekutoski MB, et al: Neurologic outcomes of complex adult spinal deformity surgery: results of the prospective, multicenter Scoli-RISK-1 Study. Spine (Phila Pa 1976) 41:204-212, 2016

7. Mummaneni PV, Shaffrey CI, Lenke LG, Park P, Wang MY, La Marca F, et al: The minimally invasive spinal deformity surgery algorithm: a reproducible rational framework for decision making in minimally invasive spinal deformity surgery. Neurosurg Focus 36(5):E6, 2014

8. Park P, Okonkwo DO, Nguyen S, Mundis GM Jr, Than KD, Deviren V, et al: Can a minimal clinically important difference be achieved in elderly patients with adult spinal deformity who undergo minimally invasive spinal surgery? World Neurosurg 86:168-172, 2016

9. Passias PG, Jalai CM, Worley N, Vira S, Marascalchi B, McClelland S III, et al: Adult spinal deformity: national trends in the presentation, treatment, and perioperative outcomes from 2003 to 2010. Spine Deform 5:342-350, 2017

10. Riley MS, Bridwell KH, Lenke LG, Dalton J, Kelly MP: Health-related quality of life outcomes in complex adult spinal deformity surgery. J Neurosurg Spine 28:194-200, 2018

11. Scheer JK, Smith JS, Clark AJ, Lafage V, Kim HJ, Rolston JD, et al: Comprehensive study of back and leg pain improvements after adult spinal deformity surgery: analysis of 421 patients with 2-year follow-up and of the impact of the surgery on treatment satisfaction. J Neurosurg Spine 22:540553,2015

12. Shamji MF, Goldstein CL, Wang M, Uribe JS, Fehlings MG: Minimally invasive spinal surgery in the elderly: Does it make sense? Neurosurgery 77 (Suppl 4):S108-S115, 2015

13. Sharif S, Afsar A: Learning curve and minimally invasive spine surgery. World Neurosurg 119:472-478, 2018

14. Smith JS, Klineberg E, Lafage V, Shaffrey CI, Schwab F, Lafage R, et al: Prospective multicenter assessment of perioperative and minimum 2-year postoperative complication rates associated with adult spinal deformity surgery. J Neurosurg Spine 25:1-14, 2016

15. Uribe JS, Beckman J, Mummaneni PV, Okonkwo D, Nunley P, Wang MY, et al: Does MIS surgery allow for shorter constructs in the surgical treatment of adult spinal deformity? Neurosurgery 80:489-497, 2017

16. Uribe JS, Deukmedjian AR, Mummaneni PV, Fu KM, Mundis GM Jr, Okonkwo DO, et al: Complications in adult spinal deformity surgery: an analysis of minimally invasive, hybrid, and open surgical techniques. Neurosurg Focus 36(5):E15, 2014

17. Uribe JS, Januszewski J, Wang M, Anand N, Okonkwo DO, Mummaneni PV, et al: Patients with high pelvic tilt achieve the same clinical success as those with low pelvic tilt after minimally invasive adult deformity surgery. Neurosurgery 83:270-276, 2018

18. Wang MY: Improvement of sagittal balance and lumbar lordosis following less invasive adult spinal deformity surgery with expandable cages and percutaneous instrumentation. J Neurosurg Spine 18:4-12, 2013

19. Wang MY, Bordon G: Mini-open pedicle subtraction osteotomy as a treatment for severe adult spinal deformities: case series with initial clinical and radiographic outcomes. J Neurosurg Spine 24:769-776, 2016

20. Wang MY, Mummaneni PV, Fu KM, Anand N, Okonkwo DO, Kanter AS, et al: Less invasive surgery for treating adult spinal deformities: ceiling effects for deformity correction with 3 different techniques. Neurosurg Focus 36(5):E12, 2014

21. Wang T, Han C, Jiang H, Tian P: The effect of obesity on clinical outcomes after minimally invasive surgery of the spine: a systematic review and meta-analysis. World Neurosurg 110:e438-e449, 2018

22. Yen CP, Mosley YI, Uribe JS: Role of minimally invasive surgery for adult spinal deformity in preventing complications. Curr Rev Musculoskelet Med 9:309-315, 2016

\section{Disclosures}

Dr. Wang is a consultant for DePuy-Synthes Spine, Stryker, K2M, and Spineology; he is a patent holder with DePuy-Synthes Spine; and he has direct stock ownership in ISD, Spinicity, and Medical Device Partners. Dr. Eastlack is a consultant for Aesculap, Baxter, K2M-Stryker, NuVasive, Seaspine, SI-Bone, Spine Innovation, Carevature, and Titan; receives royalties from Globus Medical; has direct stock ownership in Carevature, DiFusion, NuVasive, Alphatec, Spine Innovation, Seaspine, and Invuity; has received clinical or research support from NuVasive, Scripps Clinic Medical Group, and Seaspine for the study described; and holds patents with Invuity, Globus Medical, NuVasive, Aesculap, Spine Innovation, and NuTech. Dr. Park is a consultant for Globus Medical, NuVasive, AlloSource, and Medtronic; receives royalties from Globus Medical; and receives research support from Pfizer and Vertex. Dr. Nunley is a consultant for K2M, Zimmer Biomet, Spineology, Vertiflex, Camber, Integrity, and Centinel; receives royalties from K2M and LDR; has stock or stock options in Amedica, Paradigm Spine, Camber, and Spineology; holds patents with K2M, Zimmer Biomet, Camber, and Integrity; and receives research support from Mesoblast, Organogenesis, Pfizer, Seikagaku, Simplify, Spinal Kinetics, Spineology, Vertiflex, and Zimmer Biomet. Dr. Kanter receives royalties from and is a consultant for NuVasive and Zimmer Biomet. Dr. Uribe is a consultant for NuVasive, SI-Bone, and Misonix; receives royalties, research support, and has stock options in NuVasive. Dr. Anand is a consultant for Medtronic and Spinal Balance; has direct stockownership in Atlas Spine, Globus Medical, GYS Tech, Medtronic, Paradigm Spine, Spinal Balance, and Theracell; is a patent holder with Medtronic; and receives royalties from Medtronic, Globus Medical, and Elsevier. Dr. Okonkwo is a consultant for NuVasive, Zimmer Biomet, and Stryker; is a patent holder with Zimmer Biomet; and receives royalties from Zimmer Biomet and NuVasive. Dr. Than is a consultant for Bioventus and Medtronic. Dr. Shaffrey is a consultant for Medtronic, NuVasive, Siemans, and EOS; has direct stock ownership in NuVasive; and is a patent holder with Medtronic, NuVasive, and Zimmer Biomet. Dr. Lafage has direct stock ownership in Nemaris, Inc.; receives support from DePuy Synthes Spine, NuVasive, K2M, Medtronic, Globus, AlloSource, Orthofix, SI-Bone, and Stryker for non-study-related clinical or research effort; receives grants from NASS and SRS; and has speaking/teaching arrangements with AOSpine, DePuy Synthes Spine, and K2M. Dr. Mundis is a consultant for NuVasive, K2M, Viseon, Seaspine, and AlloSource; receives royalties from $\mathrm{K} 2 \mathrm{M}$ and NuVasive; has direct stock ownership in NuVasive; holds a patent with $\mathrm{K} 2 \mathrm{M}$; has a personal relationship with Global Spine Outreach and San Diego Spine Foundation; and is a speaker for DePuy. Dr. Mummaneni is a consultant for Globus, DePuy Synthes Spine, and Stryker; has direct stock ownership in Spinicity/ISD; receives support from NREF and AOSpine for a non-study-related clinical or research effort; receives honoraria from AOSpine and Spineart; receives support from ISSG for the study described; and receives royalties from DePuy Spine, Thieme Publishing, Taylor \& Francis, and Springer Publishing.

\section{Author Contributions}

Conception and design: Wang. Drafting the article: Wang. Critically revising the article: Uribe, Anand. Reviewed submitted version of manuscript: Tran, Brusko, Eastlack, Park, Nunley, Kanter, Uribe, Anand, Okonkwo, Than, Shaffrey, Lafage, Mundis, Mummaneni. Approved the final version of the manuscript on behalf of all authors: Wang.

\section{Correspondence}

Michael Y. Wang: Lois Pope LIFE Center, Miami, FL. mwang2@ med.miami.edu. 